\title{
In vitro maturation, apoptotic gene expression and incidence of numerical chromosomal abnormalities following cryotop vitrification of sheep cumulus-oocyte complexes
}

\author{
Bita Ebrahimi • Mojtaba Rezazadeh Valojerdi • \\ Poopak Eftekhari-Yazdi • Hossein Baharvand
}

Received: 23 November 2009 / Accepted: 11 February 2010 / Published online: 9 March 2010

(C) Springer Science+Business Media, LLC 2010

\begin{abstract}
Purpose The purpose of this study was to evaluate the effects of cryotop vitrification of sheep cumulus-oocyte complexes (COCs) on oocyte maturation, apoptotic gene expression and incidence of chromosomal abnormalities. Methods Freshly isolated (control group) and vitrifiedwarmed COCs (cryotop group) were matured in vitro. The expression of pro- and anti-apoptotic genes was investigated by real-time PCR. The incidence of numerical chromosomal abnormalities was evaluated by cytogenetic analysis. Results The mean percentage of oocytes in the cryotop and control groups that reached metaphase II was $49.25 \pm 3.01 \%$ and $51.94 \pm 2.7 \%$ respectively. The expression rates of proand anti-apoptotic genes were similar in both groups, whereas the incidence of numerical chromosomal abnor-
\end{abstract}

Capsule Apoptosis and chromosomal abnormality after oocyte vitrification.

B. Ebrahimi • M. R. Valojerdi $(\square)$

Department of Anatomy, Faculty of Medical Science,

Tarbiat Modares University,

P.O. Box: 14115-111, Tehran, Iran

e-mail: mr_valojerdi@modares.ac.ir

M. R. Valojerdi · P. Eftekhari-Yazdi

Department of Embryology, Royan Institute for Reproductive

Biomedicine Research Center, ACECR,

Tehran, Iran

H. Baharvand

Department of Stem Cells and Developmental Biology,

Royan Institute for Stem Cell Biology and Technology, ACECR,

Tehran, Iran

H. Baharvand

Department of Developmental Biology,

University of Science and Culture, ACECR,

Tehran, Iran malities was higher in the cryotop group compared to the control group ( $42.5 \%$ vs. $20 \%, p<0.05)$.

Conclusion Although cryotop vitrification of COCs did not affect the incidence of oocyte maturation or apoptotic gene expression, significant deficiencies in the maintenance of oocyte chromosomal organization were seen.

Keywords Apoptotic genes · Numerical chromosomal abnormality Cumulus-oocyte complexes · Sheep .

Vitrification

\section{Introduction}

The most efficient way to have oocytes on-call for reproductive applications is to store them under liquid nitrogen [1]. However, the larger volume and smaller surface-to-volume ratio of oocytes makes their cryopreservation more difficult, especially in mammals [2].

Currently, for gamete cryopreservation, vitrification appears to be a promising alternative to the classic slow freezing technique [3-6]. However, there are toxic effects of high cryoprotectant concentrations during vitrification; cells must tolerate a short equilibration time and a rapid cooling rate [7]. For this reason, the main effort has been to reduce the volume of vitrification solution that is used [6]. In this regard, several different cryodevices such as microscopic grids [8], open pulled straws [9], cryoloops [10], cryoleafs [11] and cryotops [12] have been used.

Cryopreservation causes a significant increase in the rate of oocyte degeneration. However, this condition can be alleviated by using vitrification, but it must be considered that different factors in vitrification such as high cryoprotectant concentrations, cooling, and osmotic stress may contribute to the initiation of apoptosis that threaten later 
viability and development [16]. However, in the absence of cryopreservation, the process of in vitro maturation also induces degeneration via an apoptotic pathway [13-15]. This pathway is also activated by such physiological stimuli as: temperature, toxicants, and oxidative stress, to name a few [16].

There are two important regulatory families involved in this process: the Bcl-2 and Caspase families. The Bcl-2 family consists of two types of members: anti-apoptotic such as Bcl-2 and Bcl-XL, and pro-apoptotic such as Bax and $\mathrm{Bid}[17,20]$. Bcl-2 is a membrane-associated protein present in the nuclear envelope and mitochondria and is fully capable of promoting germ cell survival in females irrespective to the developmental status of the oocyte [18]. The pro survival function of Bcl-2 is exerted by first modulating the mitochondrial release of cytochrome $\mathrm{c}$ causing the interaction of Apaf- 1 with caspase 9 and secondly through binding to Bax, and finally blocking apoptosis induced by C-myc [19, 20]. Bax is a member of the pro-apoptotic genes that resides either in the cytoplasm or cell membrane. Bax is a Bcl-2 antagonist whose cytoplasmic elevation is sufficient to cause induction of oocyte apoptosis [21]. Caspases, including caspase 1, 2 and 3 , also exist in cells as inactive proenzymes that become activated upon initiation of apoptosis. A number of proteins such as PARP (poly ADP ribose polymerase), histone $\mathrm{H} 1$ and lamins are destroyed by the action of caspases which lead to the morphological changes that occur in apoptotic cells [22]. The existence of intracellular caspase activity is definitive confirmation of cellular degeneration, as they are apoptosis-specific proteases; particularly caspase 3 [19]. In addition, P53 which is a stress response gene is induced by DNA damage leading to the activation of downstream effectors genes (include Bax). During this procedure, the release of mitochondrial cytochrome $\mathrm{c}$ is promoted while anti-apoptotic genes continue to function normally [19].

Some scientists believe that in most species such as bovine [23, 24] and human [25], germinal vesicle (GV) oocytes are more amenable to vitrification than metaphase II (MII) oocytes. These authors thought that the specific structure of MII oocytes, such as the cortical granules and microtubular spindles, is the main cause of this cryosensitivity [26]. Meiotic spindles are dynamic structures consisting of microtubules which concomitantly organize and disorganize during the vitrification procedure [27] and these might be affected by temperature reduction, cryoprotectant concentration and in vitro culture [28]. Disorganization of meiotic spindles might lead to chromosomal dispersion, aneuploidy or polyploidy of in vitro matured cryopreserved oocytes, as well as failure of normal fertilization and development [1]. However, post-thawing incubation could compensate for these problems to some degree, but not completely [29]. On the other hand, Gosden in a review article showed that germinal vesicle oocytes may be more sensitive to cryopreservation than MII ones, he claimed that impairing of the junctions between the oocyte and surrounding cumulus cells and vitrification of two different cell types are the main associated problems in the germinal vesicle oocyte vitrification procedure [30].

Accordingly, this study was set up to evaluate the effects of the cryotop vitrification method on sheep cumulusoocyte complexes (COCs) with respect to effects on oocyte maturation and apoptotic gene expression and also the incidence of chromosomal abnormalities.

\section{Materials and methods}

\section{Collection of immature oocytes}

Sheep ovaries from the slaughterhouse were transported to the laboratory in phosphate buffered saline supplemented with gentamycin $(0.5 \%)$, streptomycin $(50 \mathrm{mg} / \mathrm{ml})$ and penicillin $(60 \mathrm{mg} / \mathrm{ml})$ at $35-37^{\circ} \mathrm{C}$ within $2-4 \mathrm{~h}$. The COCs were aspirated from 2-6 mm diameter follicles with a 19 gauge needle fitted to a $5 \mathrm{ml}$ syringe. After aspiration, COCs were washed in HEPES-buffered tissue culture medium 199 (TCM199; Sigma M2520-1L, St. Louis, MO, USA) supplemented with $10 \%$ fetal bovine serum (FBS, Hyclone SH30088-03, Logan, UT, USA). Isolated COCs which had a fine homogenous granular oocyte cytoplasm surrounded with compact layers of cumulus cells were chosen for the experiment and randomly divided into the non-vitrified control and cryotop vitrification groups.

\section{Vitrification}

Equilibration and vitrification procedures were performed at room temperature $\left(25-27^{\circ} \mathrm{C}\right)$ as described in our previous report [31]. In brief, COCs were first equilibrated for 10 $15 \mathrm{~min}$ in a solution of $7.5 \%$ ethylene glycol (EG, Sigma 293237-1L, St. Louis, MO, USA), 7.5\% dimethyl sulfoxide (DMSO, Sigma D2650, St. Louis, MO, USA) and 20\% FBS in $\alpha$-MEM (Gibco 11900-073, Carlsbad, CA, USA) followed by vitrification for $1 \mathrm{~min}$ in a solution of $15 \% \mathrm{EG}$, $15 \%$ DMSO, $0.5 \mathrm{M}$ sucrose and 20\% FBS in $\alpha$-MEM. Samples were loaded on cryotop and preserved in liquid nitrogen for one week.

\section{Warming}

After one week, the cryotops were plunged into preincubated $\alpha$-MEM, 20\% FBS and $1 \mathrm{M}$ sucrose solution for $1 \mathrm{~min}$; COCs were then sequentially rehydrated in $\alpha$-MEM and $20 \%$ FBS $(\mathrm{v} / \mathrm{v})$ containing 0.5 and $0.25 \mathrm{M}$ sucrose at 
room temperature for 3-5 min in each, respectively. Finally, the COCs were rinsed in $\alpha$-MEM and 20\% FBS.

\section{Assessment of COCs viability}

Two hours after warming, COCs were examined under a stereomicroscope with $20 \times$ magnification. Healthy and degenerated COCs were assessed according to the criteria in our previous report [31]. Briefly, COCs with intact and homogenous ooplasm and undamaged cumulus cells were considered as healthy and COCs with dark ooplasm and damaged cumulus cells categorized as degenerate.

In vitro maturation

Fresh COCs (control group) and the vitrified COCs (cryotop group) were transferred into maturation medium for 20 $22 \mathrm{~h}$ at $39^{\circ} \mathrm{C}$ in a humidified atmosphere of $5 \% \mathrm{CO}_{2}$ in air. The maturation medium was composed of: TCM199 (Sigma M5017-1L, St. Louis, MO, USA) supplemented with $10 \%$ FBS, $0.02 \mathrm{U} / \mathrm{ml}$ bFSH (Sioux Biochemicals 715, IA, USA), 0.02U/ml bLH (Sioux Biochemicals 725, IA, USA), $1 \mu \mathrm{g} / \mathrm{ml}$ estradiol- $17 \beta, 0.2 \mathrm{mM}$ sodium pyruvate, $50 \mu \mathrm{g} / \mathrm{ml}$ kanamycin, $100 \mu \mathrm{M}$ cysteamine [32]. To assess maturation, the oocytes were stained with a supra vital concentration of Hoechst (Sigma B2261, St. Louis, MO, USA), 20-22 $\mathrm{h}$ after in vitro maturation.

Sample collection, RNA isolation and reverse-transcription

To evaluate apoptotic gene expression in COCs, from each experimental group 60 to 100 COCs (all healthy and degenerated COCs) were collected after maturation, centrifuged, lysed with RLT buffer (RNeasy Lyser Tissue, Qiagen, Europe) and stored at $-70^{\circ} \mathrm{C}$. Total RNA was isolated using an RNeasy Micro Kit (Qiagen, Europe) according to the manufacturer's instructions. Sample purity was assessed using the A260/A280 nm ratio with expected values between 1.8 and 2.0. For genomic DNA removal, RNA samples were treated with $1 \mathrm{U} / \mu \mathrm{l}$ of RNase-free DNaseI (Fermentas, UK) per $1 \mu \mathrm{g}$ of RNA in the presence of $40 \mathrm{U} / \mu \mathrm{l}$ of ribonuclease inhibitor (Fermentas, UK) in $1 \times$ reaction buffer with $\mathrm{MgCl}_{2}$ for $30 \mathrm{~min}$ at $37^{\circ} \mathrm{C}$. To inactivate DNaseI, $1 \mu 1$ of $25 \mathrm{mM}$ EDTA was added and incubated at $65^{\circ} \mathrm{C}$ for $10 \mathrm{~min}$.

Reverse-transcription reactions were performed with $0.5-1 \mu \mathrm{g}$ total RNA using a RevertAid ${ }^{\mathrm{TM}} \mathrm{H}$ minus First Strand cDNA Synthesis Kit (Fermentas, UK) and random hexamer as a primer, according to the manufacturer's instructions. For each sample, minus reverse transcriptase controls were prepared using the identical procedure in cDNA synthesis except for the omission of the reverse transcriptase.
Real-time polymerase chain reaction

Gene expression was assessed by quantitative RT-PCR. Primers of the apoptotic genes (C-myc, P53, Bax, Bcl2 and Caspase 3) and housekeeping genes (ACTB and B2M) were first designed on primer design software (Primer3 Primers Sequence; Whitehead Institute for Biomedical Research, USA). The expected fragment sizes are listed in Table 1. The PCR mix in each well included the following: $12.5 \mu$ of Power SYBR ${ }^{\circledR}$ Green PCR Master Mix (Applied

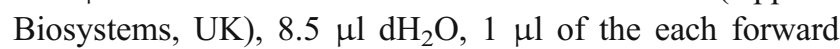
and reverse primers $(5 \mathrm{pmol} / \mu \mathrm{l})$, and $2 \mu \mathrm{l}$ of single strand cDNA $(12.5 \mathrm{ng} / \mu \mathrm{l})$ in a final reaction volume of $25 \mu \mathrm{l}$. The PCR run was carried out on an ABI 7500 Real-Time PCR System (Applied Biosystems) using the following program: stage $1: 95^{\circ} \mathrm{C}$ for $10 \mathrm{~min}$, stage $2: 95^{\circ} \mathrm{C}$ for $15 \mathrm{~s}$ and $60^{\circ} \mathrm{C}$ for $1 \mathrm{~min}$, for a total of 40 cycles, and stage $3: 95^{\circ} \mathrm{C}$ for $15 \mathrm{~s}, 60^{\circ} \mathrm{C}$ for $15 \mathrm{~s}$, and $95^{\circ} \mathrm{C}$ for $15 \mathrm{~s}$. The last heating step in stage 3 was performed with a ramp rate of $2 \%$ in order to enable the generation of a dissociation curve of the product. Product specificity was confirmed in the initial experiments by $3 \%$ agarose gel electrophoresis and routinely by dissociation curve analysis. All samples were run in duplicate and the mean value of each duplicate was used for all further calculations. Reverse transcriptase minus samples and no template controls were run together with test samples. The output data as generated by Sequence Detection System 1.4 software (Applied Biosystems) were transferred to Microsoft Excel for analysis.

The relative expression ratios were calculated by a mathematical model, which included an efficiency correction for real-time PCR efficiency of the individual transcripts [33], as follows: Ratio $=(\mathrm{E}$ target $) \Delta \mathrm{Ct}$ target (control-sample)/(E ref) $\Delta \mathrm{Ct}$ ref (control-sample).

Table 1 Primer sequences, expected fragment sizes of apoptotic and housekeeping genes

\begin{tabular}{|c|c|c|}
\hline Genes & Primer sequences $\left(5^{\prime}-3^{\prime}\right)$ & Size (bp) \\
\hline P53 & $\begin{array}{l}\text { F: GGAAGAATCGCAGGCAGAACT } \\
\text { R: GGAGAGCTCGGAGGACAGAA }\end{array}$ & 109 \\
\hline C-myc & $\begin{array}{l}\text { F: GGATAGTGGAAATACGGGCT } \\
\text { R: GTGGTAGAAGTTCTCCTCCT }\end{array}$ & 125 \\
\hline Bcl-2 & $\begin{array}{l}\text { F: GCCGAGATGTCCAGTCAGC } \\
\text { R:GACGCTCTCCACACACATGAC }\end{array}$ & 150 \\
\hline Bax & $\begin{array}{l}\text { F: CATGGAGCTGCAGAGGATGA } \\
\text { R: GTTGAAGTTGCCGTCGGAAA }\end{array}$ & 100 \\
\hline Caspase 3 & $\begin{array}{l}\text { F: TAGCAAGTTTCTTCAGAGGG } \\
\text { R: GTCTCAATACCACAGTCCAG }\end{array}$ & 105 \\
\hline ACTB & $\begin{array}{l}\text { F: CGCAGACAGGATGCAGAAAG } \\
\text { R: GCTGATCCACATCTGCTGGA }\end{array}$ & 148 \\
\hline $\mathrm{B} 2 \mathrm{M}$ & $\begin{array}{l}\text { F: TTCTGTCCCACGCTGAGTTC } \\
\text { R: CAACCCAAATGAGGCATCGT }\end{array}$ & 149 \\
\hline
\end{tabular}


The relative expression ratio of a target gene was determined from the real-time PCR efficiency (E) and the threshold cycle difference for an unknown sample versus a control (Ct control-sample). For each gene, cDNA dilution curves were generated and used to calculate the individual real-time PCR efficiencies $[\mathrm{E}=10(-1 /$ slope $)]$. The geometric mean of the two internal reference genes was used to correct the raw values for the genes of interest.

\section{Cytogenetic analysis}

Chromosomal analysis by the classical method was performed on selected oocytes from the cryotop and control groups. Oocytes were denuded after 20-22 h of maturation and those oocytes that released their first polar body and had a homogenous granular cytoplasm were freed of zona pellucida by using Tyrode's acid solution $(\mathrm{NaCl} 800 \mathrm{mg}$, $\mathrm{KCl} 20 \mathrm{mg}, \mathrm{CaCl}_{2} \cdot 2 \mathrm{H}_{2} \mathrm{O} 24 \mathrm{mg}, \mathrm{MgCl}_{2} \cdot 6 \mathrm{H}_{2} \mathrm{O} 10 \mathrm{mg}$, glucose $100 \mathrm{mg}$, polyvinyl pyrolidone $400 \mathrm{mg} / 100 \mathrm{~cm}^{3}$, deionized water, $\mathrm{pH}=2.5$ ). Oocytes were then incubated for $10-15 \mathrm{~min}$ in a hypotonic solution (1\% sodium citrate and $0.6 \% \mathrm{BSA}$ ), and fixed on glass slides in a cold mixture solution of methanol and acetic acid (concentration 3:1). The air-dried chromosomes were stained in 10\% Giemsa solution for $10 \mathrm{~min}$ and assessed under light microscope [34].

\section{Statistical analysis}

Statistical analysis was performed using the data analysis software program Statistical Package for Social Sciences (SPSS) 13.0 (SPSS, Inc, Chicago, IL, USA) for Windows. Data were first evaluated using the Kolmogrov-Smirnov normalization test. Thereafter, mean percentages of healthy and degenerated COCs, mean percentages of GV, GVBD, MII and degenerated oocytes after in vitro maturation, and the relative gene expression in both groups were compared by one-way analysis of variance (ANOVA) and post Tukey's test. All these data were expressed as mean \pm SEM. The incidence of numerical chromosomal abnormalities was assessed using the Chi-squared test. A probability of $p<$ 0.05 was considered to be statistically significant.

\section{Results}

For acquiring good maturation rates, high quality COCs (oocytes with fine homogenous granular cytoplasm and compact granulosa cell layers) with a mean diameter of $275.36 \pm 5.88 \mu \mathrm{m}$ were selected and randomly divided into two groups; non-vitrified control and cryotop vitrification (approximately 200 COCs per group with about 15 repetitions).

Initially the viability of vitrified-warmed $\mathrm{COCs}$ was assessed by observation with the stereomicroscope. Based on this observation, the oocytes of healthy vitrified-warmed COCs appeared to have contact with cumulus cells and a uniform granular cytoplasm, while the oocytes of degenerated vitrified-warmed COCs had lost their contact with surrounding cumulus cells in most areas and were slightly darker in appearance. The viability rate of healthy COCs after two hours post-warming was $81.26 \pm 2.23 \%$. However, the viability of COCs after $20-22 \mathrm{~h}$ in maturation medium, whether vitrified or not, was significantly reduced (Fig. 1A). After maturation, the mean percentage of healthy COCs was $72.23 \pm 1.87 \%$ and $71.14 \pm 3.14 \%$ in the control and cryotop groups, respectively. Statistical analysis showed that differences between the healthy oocytes before and after maturation in the control and cryotop groups were statistically significant.

At the time of maturation, Hoechst staining revealed different stages of oocyte maturation. The percentage of oocytes at the MII stage was similar between the control and cryotop groups $(51.94 \pm 2.7$ and $49.25 \pm 3.01 \%, p<$ $0.05)$. The mean percentages of germinal vesicle (GV) and germinal vesicle breakdown (GVBD) were respectively $8.65 \pm 1.28 \%$ and $12.46 \pm 1.12 \%$ in the control group versus $8.10 \pm 1.52 \%$ and $13.78 \pm 1.59 \%$ in the cryotop group. No significant differences were observed between the control and cryotop groups in these variants (Fig. 1B).

The real time PCR results for the expression profiles of the apoptotic genes, C-myc, P53, Bcl-2, Bax and Caspase 3 , were highest in the control group (reference group). The cryotop vitrification group had the relative expression levels of apoptotic genes nearest to the control group. Bax and Caspase 3 expressions were also nearly the same between the two groups. The control group showed no significant difference with the cryotop group. Details of these expressions are shown in Fig. 2.

The effects of vitrification and in vitro maturation on chromosomal organization and numerical aberrations were evaluated by cytogenetic analysis. Around 260 and 360 oocytes were analyzed in the control and cryotop groups, respectively. Amongst these, only the chromosomes of 40 oocytes in each group could be counted (Fig. 3). This problem was due to the low efficiency of the classical method of chromosomal analysis. However the frequency of numerical chromosomal abnormalities was $20 \%$ and $42.5 \%$ in the control and cryotop groups (Table 2) and a significant difference was observed between these groups $(p$ value $\leq 0.05)$. The Chi value for this test was 4.71 .

\section{Discussion}

Our objective in this study was to evaluate the effects of the cryotop vitrification method on sheep COCs 

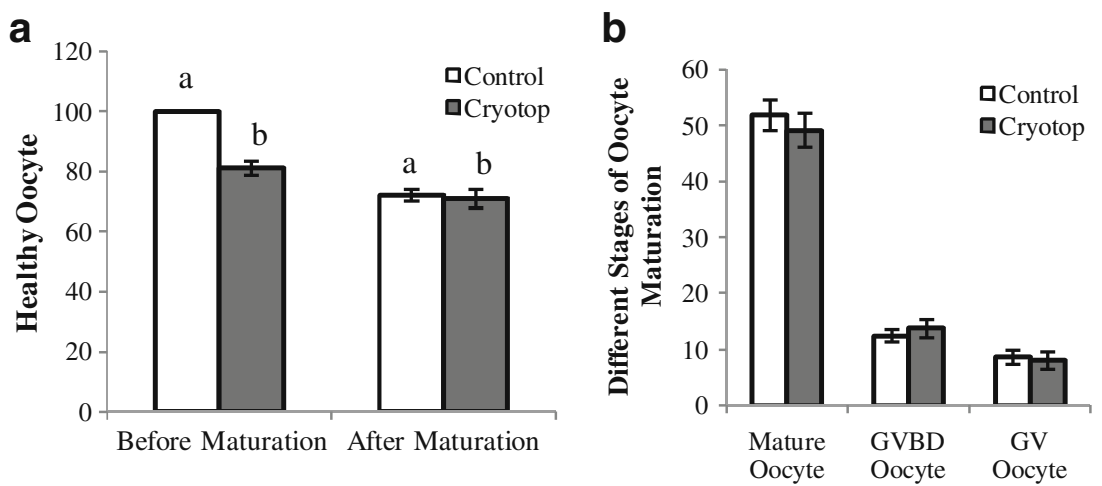

Fig. 1 (A) Healthy oocytes before and after in vitro maturation, (B) Different nuclear stages of oocytes in the control and cryotop groups. Note: Same superscripts show significant difference. a $(p$ value $\leq 0.0001) ; \mathrm{b}(p$ value $=0.003)$

viability, maturation, apoptosis and numerical chromosomal abnormalities.

Presence of lipid droplets and vacuoles in the ooplasm of sheep oocytes is an important obstacle in the way of oocyte cryopreservation; lipid droplets make oocytes more sensitive to cooling, causing irreversible injuries to membrane structures at low temperatures [35-37]. Also the number and structure of lipid droplets in different species can cause different cryosensitivity injuries for oocytes [38]. Some researchers deplete lipid droplets from the oocyte cytoplasm before cryopreservation [35]. However, without manipulation of lipid droplets, successful results have been acquired in the present study after vitrification and warming. This success might be due to the type of cryodevice used, the minimum vitrification solution method, and combination of EG and DMSO or a high rapid cooling rate.

It was demonstrated that compact layers of cumulus cells around the oocyte could control the penetration of high toxic cryoprotectants, prevent swelling during cryoprotectant removal, and finally cause productive vitrification [39]. In agreement Vajta [40], as well as Cetin and Bastan [41] demonstrated that cumulus layers and glycoproteins around the oocyte may decrease the speed of cryoprotectant

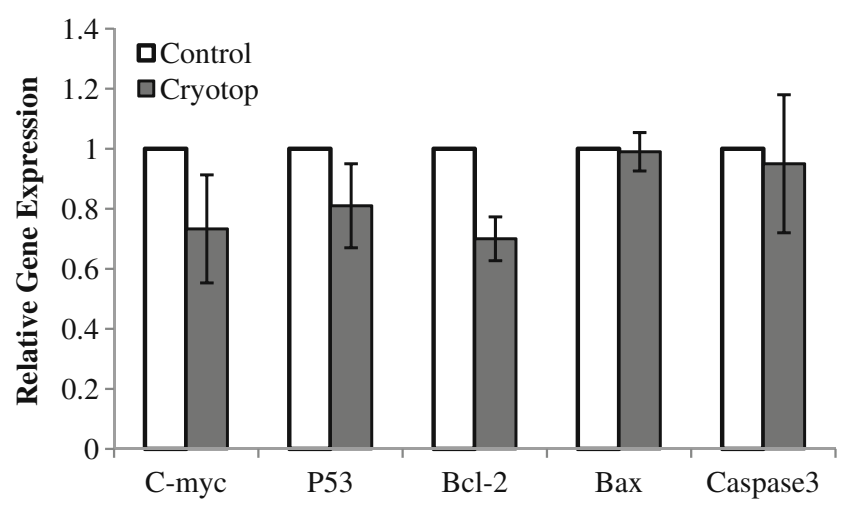

Fig. 2 Fold differences of expression of relative apoptotic genes in the cryotop and control groups. Note: Data is shown as mean \pm SEM penetration. Cumulus cells also play an important role in the in vitro maturation and development of oocytes [42]. The latter groups have shown that communication between these two types of cells occurs in a paracrine manner and that gap junctions are necessary to mediate hormonal support produced by the action of FSH. Accordingly, selection of COCs with at least three compact layers of cumulus cells could protect the oocytes and answer the need for the presence of cumulus cells in the in vitro maturation process.

In the present research, we considered previous reports $[31,35]$ and used the combination of EG and DMSO for $\mathrm{COC}$ vitrification. As expected, good survival of COCs was obtained after vitrification. This good survival rate was not due solely to the cryoprotectant combination, but also to the multistep dilution in the warming procedure. This multistep dilution has an important role in the prevention of sudden osmolarity changes that could happen during the one step dilution method [43].

The measures of apoptotic markers can be considered as an effective tool for evaluating the viability of COCs following vitrification. In the apoptosis induction and execution process, four general stages occur which involve different types of genes. The first stage is the reception of a lethal stimulus by the cell. In stage two, one or more early signaling molecules such as caspase 8 , P53 or C-myc are activated. These immediate-early signals are relayed into central regulators (such as $\mathrm{Bax}$ and $\mathrm{Bcl}-2$ ) at stage three for integration in which the final decision for life or death is made. If apoptosis is to be the outcome, the fourth stage that comprises the effectors molecules (such as Caspase 3) will initiate [44].

In this study, the control group was the reference group so any similarities in expression levels of the apoptotic genes with the cryotop group would prove the success of the vitrification process. The expression levels of the apoptotic genes were approximately the same in both groups with even the expressions of Bax and Caspase 3 
Fig. 3 Normal and abnormal chromosome number in mature oocytes. (A\&B) control group, (C\&D) cryotop group. Original magnification: $1000 \times$

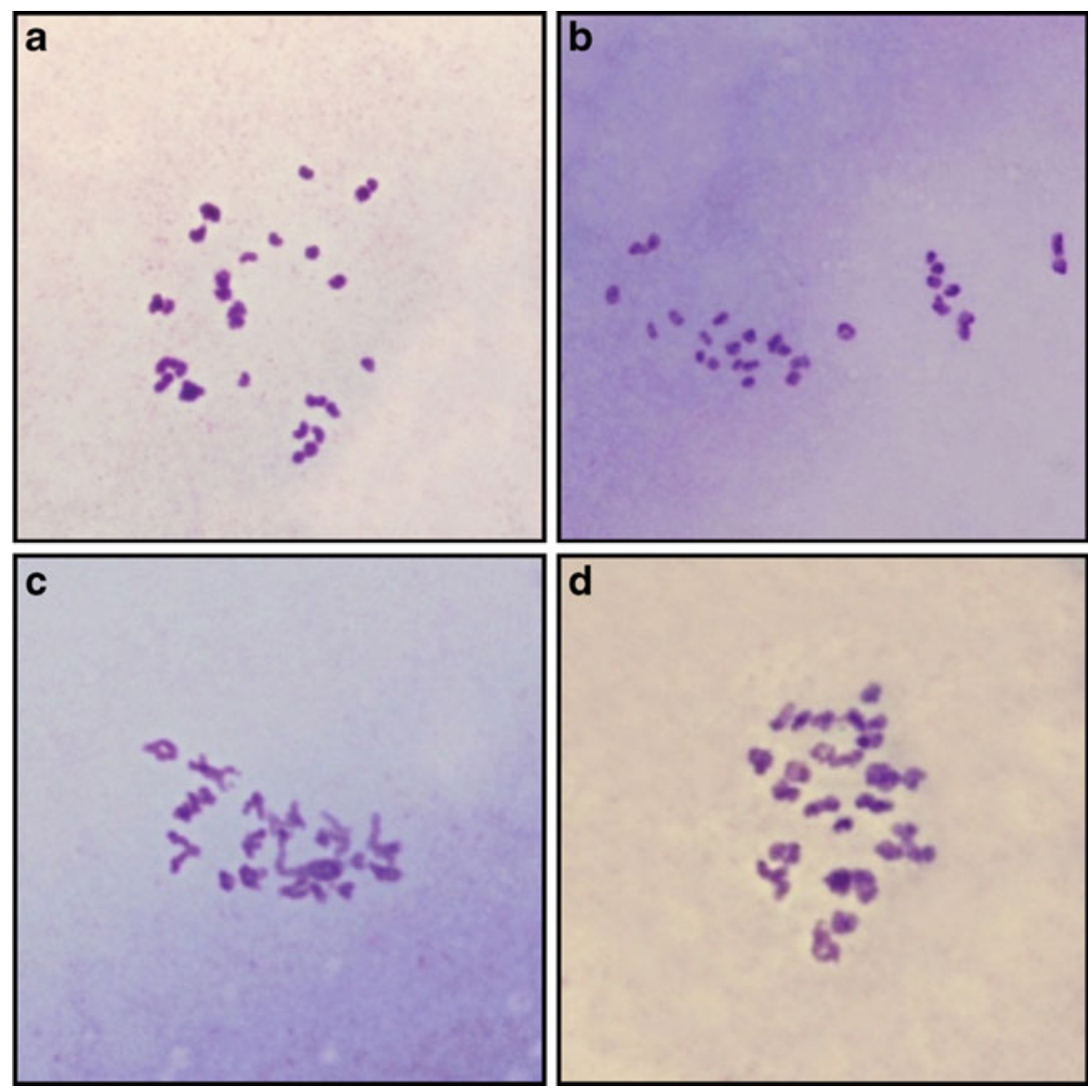

being nearly equal. Nevertheless, Bcl-2 (anti-apoptotic gene) expression was slightly lower in the cryotop group in comparison with the control group. This might be the cause of lower maturation of cryotop as compared with the control group. These results showed that cryotop vitrification did not induce apoptosis; however it was completely supportive in maintaining cell viability. It seems likely that cell death in the cryotop vitrification procedure has occurred through another pathway. In agreement with mentioned results, some researchers showed that the expression of apoptotic genes in the follicles derived from vitrified-warmed ovarian tissue strips were similar to the control group and no sign of ultrastructurally apoptosis were seen in the vitrified follicles [45]. Additionally, Anchamparuthy et al. [46] demonstrated that transcript levels of Fas, FasL, Bax and Bcl-2 increased post

Table 2 Cytogenetic assessment of the fresh and vitrified oocytes in the control and cryotop groups

\begin{tabular}{lccc}
\hline Groups & Total Oocyte & Normal Oocyte & Abnormal Oocyte \\
\hline Control & 40 & $32(80)^{\mathrm{a}}$ & $8(20)^{\mathrm{b}}$ \\
Cryotop & 40 & $23(57.5)^{\mathrm{a}}$ & $17(42.5)^{\mathrm{b}}$ \\
\hline
\end{tabular}

Values in parenthesis show percentages. Same superscripts show significant difference ( $p$ value $\leq 0.05)$. vitrification-warming and maturation of germinal vesicle oocytes but despite of their prospect any evidence of related apoptosis were not observed in embryos derived from large numbers of vitrified oocytes.

Moreover, the microtubular structure of the oocyte meiotic spindle is highly sensitive to physical (cooling/ warming) or chemical (exposure to cryoprotectants) changes. These changes may trigger tubulin depolymerization and microtubular disassembly with deleterious effects on chromosomal organization [1]. It has been shown that only a small part of the oocytes could completely recover spindle integrity after a few hours of culture at the in vivo temperature [47]. Defects of microtubular polymerization occur because of the toxic effects of cryoprotectants and have been related both to their concentration and type [28]. In that regard Succu and her co-workers [47] showed that ovine prepubertal oocytes displayed dramatic alterations of meiotic spindles and consequently chromosomal dispersion after vitrification. In a parallel study, they showed ovine adult oocyte spindle morphology was altered after vitrification but not after an exposure to the vitrification solutions [48]. Exposing prepubertal oocytes to vitrification solutions caused spindle alterations which could not be recovered afterwards, indicating a major toxic effect of cryoprotectants on this cell type. By using new vitrification methods, meiotic spindles preserved better and showed expedited 
recovery when compared to conventional straws $[49,50]$. We have shown in our previous research that cryotop vitrification in comparison with other vitrification methods (conventional straw and solid surface) caused the highest survival and maturation rate [31]. Accordingly the cryotop vitrification method was used in this study. These immature oocytes matured in vitro but unfortunately, a significant difference in the incidence of numerical chromosomal abnormality was observed after vitrification and in vitro maturation in comparison with the control group. As the percentage of numerical chromosomal abnormality was considerable in the control group too; we could conclude that not only in vitro maturation has caused numerical chromosomal abnormality but also vitrification might accelerate this phenomenon.

\section{Conclusion}

In conclusion, the cryotop method is a useful method for preservation of sheep cumulus-oocyte complexes and did not induce apoptosis; but it could not completely restrict numerical chromosomal abnormality. Subsequent in vitro maturation of immature oocytes is an important problem in the vitrification of immature oocytes that may be related to the insufficiency of maturation medium and needs more investigation.

Acknowledgements This research was financially supported by Royan Institute. There is no conflict of interest in this article.

\section{References}

1. Chen SU, Lien YR, Chao KH, Ho HN, Yang YS, Lee TY. Effects of cryopreservation on meiotic spindles of oocytes and its dynamis after thawing: clinical implications in oocyte freezing- a review article. Mol Cell Endocrinol. 2003;202:101-7.

2. Fabbri R, Porcu E, Marsella T, Primavera MR, Rocchetta G, Ciotti PM, et al. Technical aspects of oocyte cryopreservation. Mol Cell Endocrinol. 2000;169:39-42.

3. Vajta G, Kuwayama M. Improving cryopreservation systems. Theriogenology 2006;65:236-44.

4. Pegg DE. The role of vitrification techniques of cryopreservation in reproductive medicine. Hum Fertil. 2005;8:231-9.

5. Pukazhenthi BS, Comizzoli P, Travis AJ, Wildt DE. Applications of emerging to the study and conservation of threatened and endangered species. Reprod Fertil Dev. 2006;18:77-90.

6. Larman MG, Katz-Jaffe MG, Sheehan CB, Gardner DK. 1, 2 Propandiol and the type of cryopreservation adversely affect mouse oocyte physiology. Hum Reprod. 2006;22(1):250-9.

7. Jain JK, Paulson RJ. Oocyte cryopreservation. Fertil Steril. 2006;86 Suppl 3:1037-46.

8. Martino A, Songsasen N, Leibo SP. Development into blastocysts of bovine oocytes cryopreserved by ultra-rapid cooling. Biol Reprod. 1996;54:1059-69.

9. Vajta G, Holm P, Kuwayama M, Booth PJ, Jacobsen H. Open pulled straw (OPS) vitrification: a new way to reduce cryoinjuries of bovine ova and embryos. Mol Reprod Dev. 1998;51:53-8.

10. Lane M, Scholcraft WB, Gardener DK. Vitrification of mouse and human blastocysts using a novel cryoloop container-less technique. Fertil Steril. 1999;72:1073-8.

11. Chian RC, Son WY, Huang JY, Cui SJ, Buckett WM, Tan SL. High survival rates and pregnancies of human oocytes following vitrification: preliminary report. Fertil Steril. 2005;84 Suppl 1: S36.

12. Kuwayama M, Kato O. All-around vitrification method for human oocytes and embryos. J Assist Reprod Genet. 2000;17:477.

13. Hinck H, Smissen PVD, Heusterpreute M, Donnay I, Hertogh RD, Pampfer S. Identification of caspase 3 and caspase-activated deoxyribonuclease in rat blastocysts and their implication in the induction of chromatin degradation (but not nuclear fragmentation) by high glucose. Biol Reprod. 2001;64:555-62.

14. Neuber E, Luetjens CM, Chan AWS, Schatten GP. Analysis of DNA fragmentation of in vitro cultured bovine blastocyts using TUNEL. Theriogenology 2002;57:2193-202.

15. Yang MY, Rajamahendran R. Expression of bcl-2 and Bax proteins in relation to quality of bovine oocytes and embryos produced in vitro. Anim Reprod Sci. 2002;70:159-69.

16. Men H, Monson RL, Parrish JJ, Rutledge JJ. Degeneration of cryopreserved bovine oocytes via apoptosis during subsequent culture. Cryobiology 2003;47:73-181.

17. Antonsson B, Martinou JC. The Bcl-2 protein family. Exp Cell Res. 2000;256:50-7.

18. Flaws JA, Hirshfield AN, Hewitt JA, Babus K, Furth PA. Effect of $\mathrm{Bcl}-2$ on the primordial follicle endowment in the mouse ovary. Biol Reprod. 2001;64:1153-9.

19. Hussein MR. Apoptosis in the ovary: molecular mechanism. Hum Reprod Update. 2005;11(2):162-78.

20. Kim MR, Tilly JL. Current concepts in Bcl-2 family member regulation of female germ cell development and survival. Biochem Biophys Acta. 2004;1644:205-10.

21. Morita Y, Tilly JL. Oocyte apoptosis: like sand through an hourglass. Dev Biol. 1999;213:1-17.

22. Mockridge JW, Benton EC, Andreeva DS, Latchman MS, Marber MS, Heads RJ. IGF-1 regulates cardiac fibroblast apoptosis induced by osmotic stress. Biochem Biophys Res Commun. 2000; 273:322-7.

23. Men H, Monson RL, Rutledge JJ. Effect of meiotic stages and maturation protocols on bovine oocytes resistance to cryopreservation. Theriogenology 2002;57(3):1095-103.

24. Albarracin JL, Morato R, Izquierdo D, Mogas T. Vitrification of calf oocytes: effects of maturation stage and prematuration treatment on the nuclear and cytoskeletal components of oocytes and their subsequent development. Mol Reprod Dev. 2005; 72:239-49.

25. Boiso I, Marti M, Santalo J, Ponsa M, Barri PN, Veiga A. Confocal microscopy analysis of the spindle and chromosome configuration of human oocytes cryopreserved at the germinal vesicle and methaphase II stage. Hum Reprod. 2002;17:1885-91.

26. Ambrosini G, Andrisani A, Porcu E, Rebellato E, Revelli A, Caserta D, et al. Oocytes cryopreservation: state of art. Reprod Toxicol. 2006;22:250-62.

27. Zhou J, Shu HB, Joshi HC. Regulation of tubulin synthesis and cell cycle progression in mammalian cells by gamma-tubulinmediated microtubule nucleation. J Cell Biochem. 2002;84:47283.

28. Van der Elst J, Van den Abbeel E, Nerinckx S, Van Steirteghem A. Parthenogenetic activation pattern and microtubular organization of the mouse oocyte after exposure to 1, 2 propandiol. Cryobiology 1992;29:549-62.

29. Gook DA, Osborn SM, Johnston WIH. Cryopreservation of mouse and human oocytes using 1, 2 propandiol and the 
configuration of the meiotic spindle. Hum Reprod. 1993;8:11019.

30. Gosden RG. Prospects for oocyte banking and in vitro maturation. JNCI Monog. 2005;34:60-3.

31. Ebrahimi B, Valojerdi MR, Yazdi PE, Baharvand H, Farrokhi A. IVM and gene expression of sheep cumulus-oocyte complexes following vitrification by different methods. Reprod Biomed Online. 2010;20(1):26-34

32. Keefer CL, Keystone A, Lazaris A, Bhatia B, Begin I, Bilodeau AS, et al. Production of cloned goat after nuclear transfer using adult somatic cells. Biol Reprod. 2002;66:199-203.

33. Pfaffl MW. A new mathematical model for relative quantification in real-time RT-PCR. Nucleic Acids Res. 2001;29:e45.

34. Barekati Z, Gourabi H, Valojerdi MR, Yazdi PE. Previous maternal chemotherapy by cyclophosphaminde (CP) causes numerical chromosome abnormalities in preimplantation mouse embryos. Reprod Toxicol. 2008;26:278-81.

35. Gupta MK, Uhm SJ, Lee HT. Cryopreservation of immature and in vitro matured porcine oocytes by solid surface vitrification. Theriogenology 2007;67:238-48.

36. Genicot G, Leroy JL, Van Soom A, Donnay I. The use of a fluorescent dye, Nile red, to evaluate the lipid content of single mammalian oocytes. Theriogenology 2005;63:1181-94.

37. Pereira RM, Marques CC. Animal oocyte and embryo cryopreservation. Cell Tissue Banking. 2008;9:267-77.

38. Isachenko V, Isachenko E, Michelmann HW, Alabart JL, Vazquez $\mathrm{I}$, Bezugly $\mathrm{N}$, et al. Lipolysis and ultrastructure changes of intracellular vesicles after cooling of bovine and porcine $\mathrm{GV}$ oocytes. Anat Histol Embryol. 2001;30:333-8.

39. Miyake T, Kasai M, Zhu SE, Sakurai T, Machida T. Vitrification of mouse and embryos at various stages of development in an ethylene glycol-based solution by a simple method. Theriogenology 1993;40:121-4.

40. Vajta G. Oocytes and embryo vitrification. Annual ESDAR Conference 1999; 45-48.
41. Cetin Y, Bastan A. Cryopreservation of immature bovine oocytes by vitrification in straws. Anim Reprod Sci. 2006;92:29-36.

42. Shirazi A, Shams-Esfandabadi N, Hosseini SM, Karimi I. The presence of cumulus cells on nuclear maturation of sheep oocytes during in vitro maturation. Small Rumin Res. 2007;68:291-5.

43. Cuello C, Gill MA, Parrilla I, Tornel J, Vazquez JM, Roca J. In vitro development following one-step dilution of OPS-vitrified porcine blastocysts. Theriogenology 2004;62:1144-52.

44. Morita Y, Perez GI, Paris F, Miranda S, Ehleiter D, HaimovitzFriedman A, et al. Oocyte apoptosis is suppressed by disruption of the acid sphingomyelinase gene or by sphingosine-1-1phosphate therapy. Nat Med. 2000;6:1109-14.

45. Mazoochi T, Salehnia M, Pourbeiranvand S, Forouzandeh M, Mowla SJ, Hajizadeh E. Analysis of apoptosis and expression of genes related to apoptosis in cultures of follicles derived from vitrified and non-vitrified ovaries. Mol Hum Reprod. 2009;15 (3): $155-64$.

46. Anchamparuthy V, Pearson R, Gwazdauskas F. Expression pattern of apoptotic genes in vitrified-thawed bovine oocytes. Reprod Domest Anim 2009; Epub ahead of print

47. Succu S, Leoni GG, Berlinguer F, Madeddu M, Bebbere D, Mossa F, et al. Effect of vitrification solutions and cooling upon in vitro matured prepubertal ovine oocytes. Theriogenology 2007;68:107-14.

48. Succu S, Leoni GG, Bebbere D, Berlinguer F, Mossa F, Bogliolo L, et al. Vitrification devices affect structural and molecular status of in vitro matured ovine oocytes. Mol Reprod Dev. 2007;74:1337-44.

49. Chen SU, Lien YR, Cheng YY, Chen HF, Ho HN, Yang YS. Vitrification of mouse oocytes using closed pulled straws (CPS) achieves a high survival and preserves good patterns of meiotic spindles, compared with conventional straws, open pulled straws (OPS) and grids. Hum Reprod. 2001;16(11):2350-6.

50. Chen SU, Lien YR, Chen HF, Chao KH, Ho HN, Yang YS. Open pulled straws for vitrification of mature mouse oocytes preserve patterns of meiotic spindles and chromosomes better than conventional straws. Hum Reprod. 2000;15:2598-603. 